\title{
PROSTITUIÇÃO E TRÁFICO DE ADOLESCENTES
}

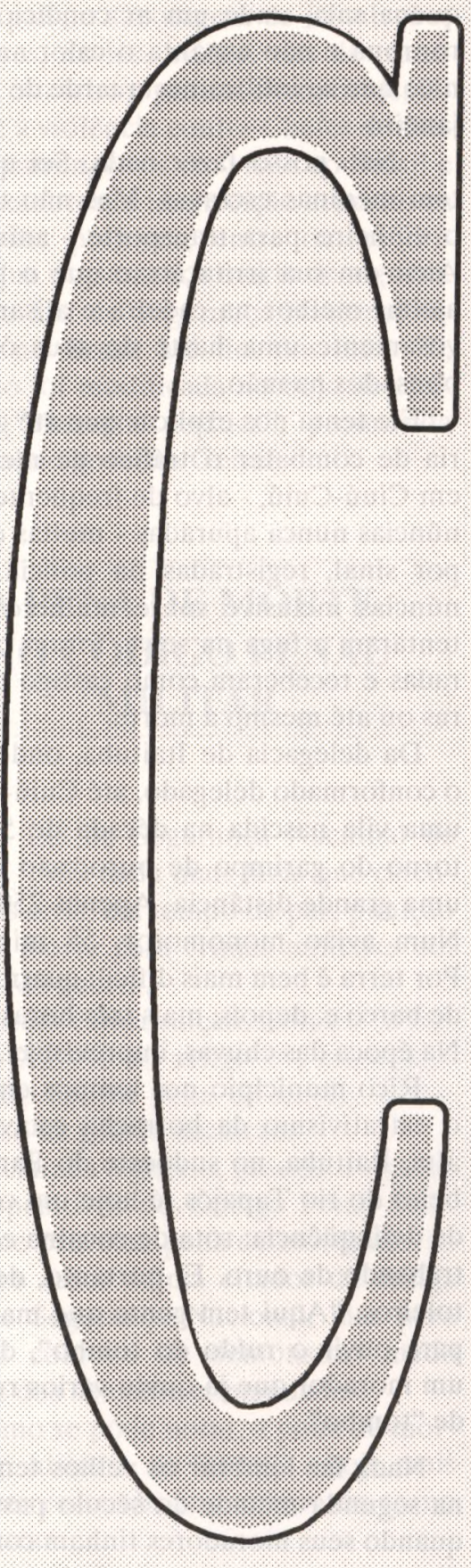

Gilberto Dimenstein*

onvido o leitor a dividir comigo essa viagem pelas rotas do tráfico humano - uma das estações finais é Cuiú-Cuiú. Mas passa antes pelos segredos da prostituição infantil, que se dissemina pelo Brasil - o Centro de Defesa para a Infância e Adolescência (CBIA), do Ministério da Ação Social, lançou documento calculando em 500 mil meninas prostitutas.

O cenário da rota é exótico, desconhecido e até inacessível: Amazônia Legal, conceito que inclui fatias das regiões Nordeste (Maranhão) e Centro-Oeste (Tocantins e Mato Grosso), cerca de $61 \%$ do território nacional.

É a região que atrai o mais intenso movimento migratório, alterando com rapidez extraordinária a cara do país. Homens e mulheres de pele clara e cabelo louro vindos do Sul misturam-se com o caboclo amazônico. Misturam-se cores de pele, comidas, expressões. Muitos foram à procura de terras, outros encantados pelo ouro. De acordo com o último Censo as maiores taxas de crescimento da população foram registradas na Amazônia: Roraima (9,1\%), Rondônia (7,9\%). Mato Grosso (5,4\%) e Pará $(3,4 \%)$.

De difícil acesso por terra e até por ar (é abundante o número de aviões que se espatifam), a selva cria Estados dentro do Estado, onde a lei é a lei de quem tem mais armas, melhores pistoleiros e mais audácia. As rotas do tráfico de meninas convertidas a prostitutas é um sinal perfeito e cristalino de como esse movimento humano é desorganizado e desumano. 


\section{ITAITUBA}

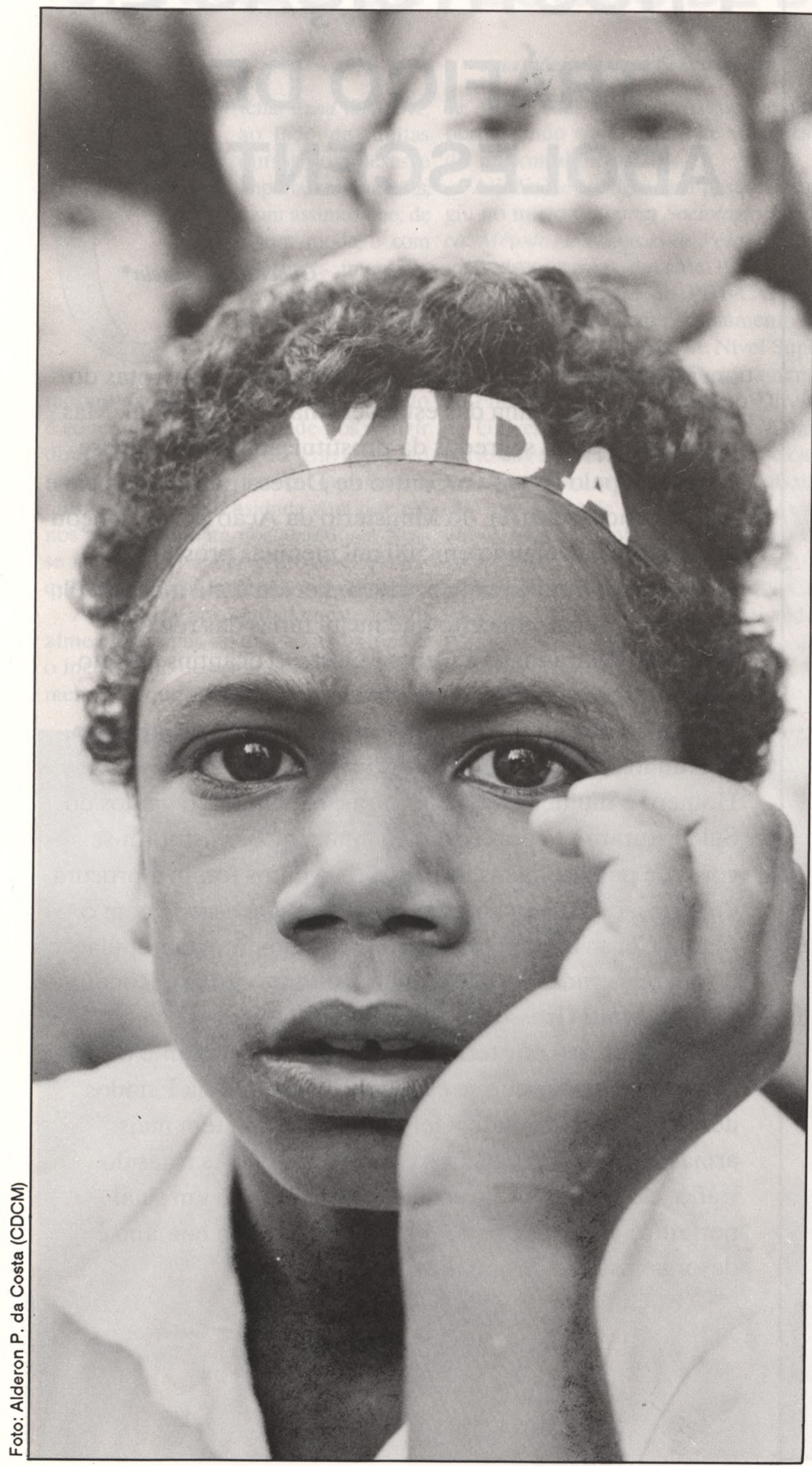

fundado na cadeira atrás de uma velha mesa, o delegado Alcir Conde não esconde um misto de enfado e irritação. Magro, barba por fazer, camisa estampada aberta no peito, seu visual não destoa do ambiente: uma pequena sala, onde um ar condicionado ronrona e não espanta o calor amazônico que se infiltra nesta tarde de 30 de janeiro.

- Não posso fazer nada. Sei que lá tem meninas escravas. Mas não temos o dinheiro para transporte - anima-se Alcir em sua irritação, o que o faz se ajeitar melhor na cadeira e alisar nervosamente uma haste de seus óculos pousados na mão.

Ele tenta nos explicar que até gostaria de combater o tráfico de meninas em Ciuú-Cuiú, - alvo de freqüentes denúncias nunca apuradas - muitas delas, por sinal, registradas na polícia. Denúncias inclusive sobre mulheres que tentaram a fuga na selva, foram capturadas e receberam como castigo torturas ou até mesmo a morte.

Da delegacia de Itaituba, onde está o conformado delegado, até Cuiú-Cuiú, uma vila nascida na década de $50 \mathrm{em}$ torno do garimpo de ouro, não existe uma grande distância. Apenas $250 \mathrm{Km}$. Num avião monomotor, 55 minutos. Por terra é bem mais difícil: quatro dias de barco e, depois, mais três horas a pé. $\mathrm{Na}$ época das chuvas, imprevisível.

Rico município nos tempos em que o extrativismo da borracha estava em alta, Itaituba, no sudoeste do Pará e à beira do rio Tapajós, é hoje um centro de delinqüência: rota de cocaína e contrabando de ouro. E, portanto, de pistoleiros. "Aqui tem gente que mata só para ouvir o ruído do tombo", define um morador que já ouviu vários ruídos de "tombo".

Nada faz lembrar os velhos tempos, na segunda metade do século passado, quando seus moradores tinham contato direto com os centros mais avançados da Europa e as moças de família liam romances em francês e a roupa dos homens da elite vinha direto de Paris. Casas e palacetes eram decorados com azulejos de Portugal. Móveis com finís- 
simo mármore Carrara.

Bastou apenas um dia para sermos abastecidos de nomes de delinqüentes e de matadores. E de detalhes sobre o funcionamento do tráfico de meninas na região de Itaituba, o maior município do mundo, com 165.578 quilômetros quadrados - uma vez e meia o Estado de Santa Catarina. É pouco menor (10 mil $\mathrm{Km}$ quadrados a menos) do que o Uruguai.

Passamos duas horas na sede da Fundação Nacional de Saúde (ex-Sucam) e os agentes de saúde, responsáveis pela vacinação na selva, disputam para saber quem tem mais casos. Todos colecionam histórias de meninas e mulheres presas. Ninguém conhece a região melhor do que eles, obrigados a percorrer cada rio e cada trilha para combater as doenças como malária, cólera, febre amarela. Entram em cada boate ou prostíbulo; alguns se fizeram amigos, amantes e confidentes de prostitutas.

Acompanhados do fotógrafo Patrich Pardini, dois pesquisadores (mantenho ơ anonimato por questão de segurança) percorreram várias áreas de garimpo. Contratados pelo convênio da Unicef com o Movimento Nacional de Meninos de Rua, organizado pelo padre Bruno Secci, eles puderam constatar o tráfico e escravidão de meninas. Passaram pelos garimpos do Crepurizinho, Crepurizão e Sudário, viajando de barco e avião.

Seu primeiro encontro foi com Márcia e Vanessa na boate Marrom Glacê no Crepurizão. Desgravadas as fitas da entrevista, eles prepararam um relatório:

Em alguns momentos nos sentimos impotentes diante das dificuldades e das tristezas de algumas das meninas com as quais conversávamos. Maria Vanessa chorou muito durante nossa entrevista. Num dos momentos declarou: "Fui enganada. Disseram que a gente ia para Itaituba trabalhar num restaurante. $A$ gente vinha domingo pra cá prum show no garimpo. Aí a gente voltava de novo. A gente vinha no domingo e na segunda a gente volta pra Itaituba pra trabalhar. Chegou, passou o domingo, mas até hoje não fomo pra Itaituba. Essa vida não é pra mim nem pra ela".
Ela, no caso, é Márcia, de 15 anos, que também foi enganada, sentada a seu lado durante a entrevista. Como Vanessa, é inexperiente. Engravidou três vezes e abortou as três vezes, tomando oito pílulas de um remédio chamado Citotec. Não tem idéia de quando vai sair dali.

Do Crepurizão, eles seguiram até o garimpo do Sudário, onde conversaram com meninas da boate Califórnia e, ali se depararam com algo comum: a malária. Uma das garotas, Edna de Oliveira, estava estendida na cama, com o corpo doído e febre, mal podia se locomover. A assistência médica é feita por algum farmacêutico que receita antibióticos. São abundantes os casos de meninas que adoecem e, com a malária mal curada, vem a hepatite. Edna se revoltava contra a situação de seu quarto, retrato da falta de higiene:

- É ridículo, dá muito carapanã, é muito sujo, é muito quente.

Um fato em particular impressionou os dois pesquisadores em toda a sua expedição. Quando estavam prestes a ir embora do Crepurizão receberam a informação de que o corpo de uma menina de 15 anos, assassinada dentro da delegacia por um policial, estava há semanas numa lixeira. A notícia de que eles estavam atrás do corpo vazou e foi, enfim, retirado antes do registro fotográfico.

Até para um brasileiro acostumado com a impunidade, causa espanto ver nos arquivos de entidades assistenciais os nomes de homens que aprisionam meninas. Nem sombra de inquéritos, prisões ou indiciamentos.

O juiz de Direito Amilcar Guimarães conforma-se ao ser indagado sobre por que a polícia não agia:

- Eu precisaria de uma polícia para controlar a polícia.

Em poucas horas de investigação, surge um apelido cercado de histórias tenebrosas: "Tampinha, o mais cruel, segundo as lendas e testemunhos, traficante de mulheres de Cuiú-Cuiú, com várias mortes nas costas. Lá, além da boate, ele dominaria áreas de garimpo, garantindo sua autoridade e o silêncio. no gatilho do revólver, auxiliado por pistoleiros. É o temido dono da boate que leva o sugestivo nome de "Mata- dor".

Nem por isso a lei do silêncio mantem-se intocável. No dia 22 de abril de 1991, Mariana dos Santos Veras, de 15 anos, foi à delegacia de polícia e contou seu drama. Tinha saído de Altamira, no Pará, com a promessa de bom emprego em Cuiú-Cuiú. Acabou no Matador, obrigada a "fazer salão" - gíria que designa prostituir-se.

Tínhamos de dormir com vários homens por noite. Quando não obedecíamos, a gente apanhava, apanhava muito - contou Mariana, que conseguiu escapar, embrenhando-se na selva.

No seu depoimento, ela deixou o nome de outras meninas que queriam fugir e não conseguiam: Raimunda Guedes (14), Zara (16), Jane (16) e Poliana (17). Todas saíram juntas de Altamira e, arrependidas, pediam socorro. Em vão.

Apenas em dezembro do ano passado, Zara Celma Cruz Teles, amiga de Mariana, libertou-se depois de amargar oito meses na boate Matador e sofrer as mais variadas espécies de maus-tratos. A fuga demorou uma semana, auxiliada por garimpeiros que se apiedaram dela. Zara também ousou dar informações à polícia.

Na boate é normal matarem e espancarem mulheres - disse, num depoimento registrado pela Fundação do Bem-Estar Social do Pará, em Itaituba.

Não é fácil acreditar em todas essas histórias. Mas não é possível que todos estivessem mentindo. Não estavam mesmo. Em 21 de dezembro do ano passado, o sociólogo Guilherme Scartezini passou por Cuiú-Cuiú, a fim de levantar dados e imagens para o Departamento Nacional de Produção Mineral (DNPM). Buscava informações sobre problemas ambientais nos garimpos da região do Tapajós, o principal ponto de extração de ouro do Brasil.

Enquanto filmava com uma SuperVHS foi chamado por duas meninas que trabalhavam na boate Luz Vermelha: Augustinéia e Socorro. Queriam ir embora e se dispuseram a pedir ajuda pela fita de vídeo, gravada pelo sociólogo.

- Minha maior vontade é sair daqui disse Augustinéia na frente da câmara, ao lado de Socorro. Ambas foram en- 
ganadas. Pensavam, como foi prometido, que trabalhariam de cozinheira. Viram-se forçadas a vender o corpo e estavam proibidas de se comunicar com a família. Lá não tem telefone, só rádio amador.

- Quando as meninas tentam fugir a polícia vai atrás - comentou Socorro.

Obtenho acesso a suplicantes cartas. Uma delas de maio de 1990, entregue à geóloga Maria Rita Rodrigues, da Secretaria de Indústria, Comércio e Mineração do Pará.

"Se a gente fugir eles vão atrás. Se encontrarem eles matam. Se eles não matam vêm batendo até a gente chegar na boate."

Mais adiante, a carta informa:

"Aqui os donos da boate bate na gente é com fio elétrico de quatro dobras. Quando eles não batem, mandam a polícia bater".

É quase um roteiro cinematográfico o relatório, ainda em rascunho, sobre as expedições da geóloga destinadas a traçar o perfil social das regiões do garimpo:

"Constatamos que uma dessas mulheres apresentou marcas de tortura.' Ela tentou fugir da corrutela (vila) e a Polícia Militar, seguindo orientação do dono da boate, a apanhou e torturou-a com uma palmatória. Alguns meses antes, uma mulher também havia tentado fugir e foi eliminada pela Polícia Militar com um tiro nas costas".

A fuga exige coragem e, acima de tudo, criatividade. Uma operação de guerra conseguiu soltar Maria Madalena Costa de Oliveira. Sua desventura começou em 28 de abril do ano passado, quando o casal Walmir e Marisa a convidou, em Altamira, para trabalhar como arrumadeira em Itaituba. Ganharia por mês 30 gramas de ouro. A viagem teve início em 4 de maio, quando chegou no hotel Miranda, em Itaituba. Ali, encontrou mais cinco moças.

A desagradável surpresa não demorou. Logo de manhã, Walmir informou que elas não ficariam na cidade. Iriam para o garimpo. Se quisessem voltar, tudo bem. Mas deveriam pagar a dívida com a passagem de avião e hospedagem. Resolveram ir. Pegaram o avião e, na pista, eram aguardadas por Tampinha.

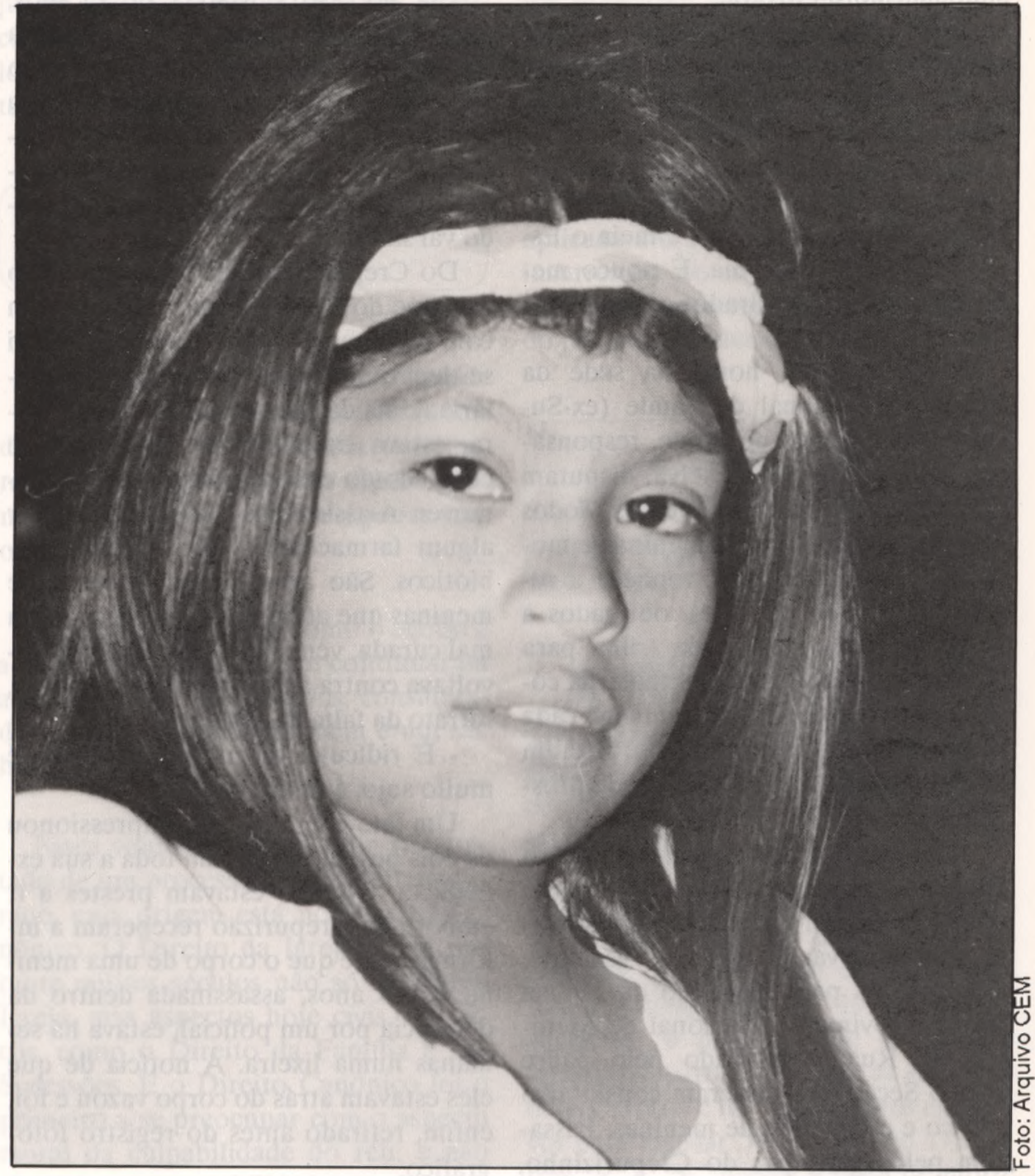

Veio a segunda surpresa desagradável do dia: teriam de trabalhar na boate Matador:

- Foram noites infernais. Tínhamos de dormir com vários homens. Éramos obrigadas a práticas homossexuais e sessões de fotografia - relata Madalena.

Depois de três meses, acompanhada das amigas Tânia e Maria de Fátima, ela tentou fugir com a ajuda de dois garimpeiros. Passaram-se duas noites e um dia, estavam cansadas devido à falta de alimentação. Chegaram à fazenda de Edmar Pereira, onde foram pedir comida. Triste idéia: o fazendeiro devolveuas ao amigo Tampinha por 49 gramas de ouro.

Não perdeu a esperança. Uma prostituta doente foi levada para Altamira e, escondida em sua bagagem, uma carta de Madalena pedindo socorro. De posse da carta, sua irmã, Raimunda
Holanda, agiu rápido. Contatou a juíza Vera Araújo de Souza, em Altamira, e procurou a polícia federal.

Acionado pela juíza, um delegado foi, em 25 de novembro, buscá-la em Cuiú-Cuiú. Na partida, a ameaça de Tampinha:

- Ele disse que se eu contasse alguma coisa me mandaria matar. Disse que se quisesse poderia me matar ali mesmo, enterrar e dando ouro para o delegado tudo seria esquecido.

A história de Maria Madalena é uma típica história de impunidade que costuma cercar o tráfico e escravidão de mulheres forçadas à prostituição. Em Belém, contou sua peregrinação pela selva não apenas à polícia civil, mas também à polícia federal. Dois deputados paraenses acompanharam o caso, além da Sociedade de Direitos Humanos. A Deputada Aida Maria 
chegou a solicitar, em requerimento na Assembléia Legislativa do Pará, a apuração imediata do tráfico de escravas.

O resultado, até ali, é que na modorrenta tarde de 30 de janeiro, um delegado limita-se a lamentar que estava de braços amarrados porque não tinha dinheiro para pegar um avião. Mas a visita à delegacia não é inútil. Muito pelo contrário. Nos seus arquivos, tem uma folha de papel que serviria como uma valiosa pista para se documentar a escravidão de meninas. O nome da pista chama-se Maria Domingas Rabelo Frazão, 14 anos.

No dia 23 daquele mês, Maria Domingas esteve naquela mesma delegacia. Informou que estava presa em Ciuú-Cuiú, mas fugiu. Desta vez o acusado não é o Tampinha, mas Mineirinho. Estava com medo: ele prometeu que, se fugisse, iria persegui-la até o inferno. Ela tinha um motivo especial para denunciá-lo: duas de suas amigas, "Tieta" e "Loura" estavam aprisionadas.

O dia está acabando - o calor vai retraindo algumas de suas garras. Vamos direto fretar um monomotor. Apenas uma empresa faz esse vôo - "Pai Velho". A pista tem dono: quem quiser entrar e sair tem de ir pela "Pai Velho". Desembolsamos US\$ 450 e marcamos a partida para as 8 horas. Mas tão urgente quanto providenciar transporte é descobrir onde mora Maria Domingas. Não tinha endereço no seu depoimento na delegacia. A única pista: Casa da Lambada, um bar na periferia da cidade.

$\mathrm{Na}$ "Casa da Lambada" teria trabalhado um namorado de "Fininha" - o apelido de Maria Domingas. Encontramos o lugar de um morador de Itaituba (seu nome vai ficar no anonimato por uma questão de segurança). Mas o namorado não estava mais lá. Escureceu. Tudo perdido. Ou quase.

Quase decididos a desistir, uma inesperada menina aponta uma inesperada pista - um parente que, talvez, soubesse como encontrá-lo. E se dispõe a subir em nossa camionete para ensinar o caminho.

Duas horas de idas e vindas pelas ruas esburacadas - para preservar a testemunha, omito o local onde pude en. contrá-la. Um homem está sentado na frente da casa. Perguntamos sobre Maria Domingas:

- Não sei quem é - responde

Insistimos. Aparece um rapaz, que pergunta num tom agressivo:

- O que vocês querem?

Desconfiado, mantem-se dentro da casa, mostrando apenas parte do rosto pela porta.

Não está - tentou encerrar a conversa, franzindo o rosto e levantando a voz.

Argumentamos que somos jornalistas, interessados em obter detalhes sobre a vida de "Fininha" em Cuiú-Cuiú e, se possível, ajudar a libertar suas amigas. Mostro minha carteira da Folha de S. Paulo. Dou o nome de alguns intermediários que ajudaram a encontrá-lo. Enquanto conversamos, a garota que nos acompanha entra na casa, reconhece "Fininha" e sai anunciando a descoberta. São necessárias mais algumas palavras para que ele, enfim, concorde. Ele explica a cautela:

- Estamos escondidos porque o $\mathrm{Mi}$ neirinho jurou que ia matar ela.

Entramos na sala da pequena casa, onde a televisão está ligada, atraindo a atenção de oito pessoas. Logo descobrimos que o desconfiado rapaz tem o apelido de baixinho e é namorado de Maria Domingas. Tímida, "Fininha" aparece ainda com os cabelos molhados do banho. Encostada na parede, cabisbaixa como se não quisesse ser reconhecida, responde as perguntas monossilabicamente. Sempre olha para o namorado a cada pergunta.

- Ele obrigava a gente a transar com todos os homens. Eu não queria. Por isso fugi.

Imaginava que iria trabalhar numa lanchonete e ganharia mais dinheiro. Logo foi enfiada num quarto da boate "Saramandaia". Demorou um mês até escapar e, agora, gostaria de ver de volta suas duas amigas - todas as três foram aliciadas com a promessa de uma vida melhor e transportadas num avião para Cuiú-Cuiú.

"Fininha" conta como funciona o esquema de escravidão. Tudo gira em torno da dívida - um saco sem fundo.
Quando a menina chega no local, é informada de que, a partir daquele momento, tem um débito - o bilhete da passagem de avião. Cerca de US\$ 100. Enquanto não pagar não pode ir embora. Só que a dívida vai aumentando com a compra de roupas, perfumes, remédios e alimentação, fornecidos pelo próprio dono da boate.

Sem prestar contas, o "proprietário" das meninas administra a despesa, tomando como base o valor da grama de ouro. Vira uma bola de neve, especialmente quando elas adoecem, coisa comum naquela região, perseguida pela malária. Não podem ganhar dinheiro e, ao mesmo tempo, sua dívida vai crescendo.

Na volta da entrevista, paramos de novo na "Casa da Lambada", onde tinha acabado de chegar uma menina do garimpo do Surubim: Vileni Reis de Almeida, 16 anos, desde os 13 fazendo "programas". Seu depoimento ajuda a mostrar como a escravidão é assimilada como um fato rotineiro, cultural até. Pergunto-lhe como foi tratada na boate. Lacônica, responde:

- Bem, ele até me deixou ir embora.

Ela ficou vários meses numa boate, trabalhava todas as noites e, mesmo assim, não conseguiu pagar a dívida. Mas, segundo ela, os donos - um casal - foram "muito legais". Deixaram que fosse embora.

- Com quanto dinheiro você voltou? - quero saber

- Nenhum.

* Gilberto Dimenstein é jormalista e Diretor da Sucursal de Brasilia da Folha de São Paulo.

\section{NOTA}

(1) Trata-se de artigo extraído do livro Meninas da Noite - a prostituição de meninas-escravas no Brasil de Gilberto Dimenstein, que está sendo lançado pela Editora Ática. 